\title{
DESTINOS INCONCLUSOS: OS JOVENS DE UMA ESCOLA DE EJA NO NORTE DO ESTADO DO ESPÍRITO SANTO
}

\author{
Fernanda Schwanz Pompermair ${ }^{1}$, Bruno dos Santos Prado Moura ${ }^{2}$ \\ Pós-graduação Lato Sensu em Proeja, Instituto Federal do Espírito Santo \\ E-mail: nandinhapom@hotmail.com, bruno.moura@ifes.edu.br
}

\begin{abstract}
RESUMO
Este trabalho trata da especificidade dos jovens no contexto da Educação de Jovens e Adultos - EJA, apresentando uma discussão conceitual dos termos identidade e juventude e, posteriormente, analisa dados recolhidos com 13 jovens da $8^{a}$ série da escola de Ensino Fundamental e Médio "Antonio dos Santos Neves", no município de Boa Esperança, norte do Estado do Espírito Santo, descrevendo suas características, no sentido de discutir sobre a identidade que eles constroem, evidenciando a existência de sua condição juvenil. O resultado da pesquisa com os jovens nos levou à construção de três categorias: o jovem em relação a si mesmo, os jovens em relação a escola e os jovens em relação ao mercado de trabalho. Os jovens aqui entrevistados revelaram semelhanças de opinião e uma postura que desmistifica visões negativas a eles atribuídas como: sem horizontes, sem perspectivas, desorientados e irresponsáveis. Mas o que se constatou é que eles se mostraram-se maduros e conscientes do papel que a escola adquire em suas vidas e de como assumem novas posturas por meio dela, principalmente no universo da EJA. A discussão dessas categorias nos permitiu entender alguns aspectos sobre a juventude no contexto da EJA, de modo a vislumbrar possibilidades de um trabalho escolar que construa o conhecimento considerando as peculiaridades e diversidade desses jovens. Esta pesquisa foi desenvolvida numa abordagem qualitativa, utilizando questionários e entrevistas.
\end{abstract}

Palavras-chave: Identidade. Juventude. Educação de Jovens e Adultos.

\section{INTRODUÇÃO}

A reflexão sobre a especificidade dos sujeitos no contexto da educação de jovens e adultos é motivadora desta pesquisa, que traz a análise da identidade educacional construída pela juventude da Educação de Jovens e Adultos - EJA, do município de Boa Esperança - ES, na tentativa de entendê-los na sua trajetória educacional.

A partir dos anos 90 pode-se evidenciar uma nova trajetória na sala de aula da EJA. Vários jovens cada vez mais cedo estão inseridos nesta modalidade de ensino e nos levam a refletir sobre a necessidade de compreendê-los, observando como se dá a entrada nessa modalidade educativa, considerando seus espaços-tempos.

Segundo Andrade (2004, p.194),

\footnotetext{
${ }^{1}$ Professora da Rede Estadual de Ensino no município de Boa Esperança, Especialista em Educação Profissional Técnica Integrada a Educação Básica na Modalidade de Jovens e Adulto.

${ }^{2}$ Mestre em educação, professor do Instituto Federal de Educação, Ciência e Tecnologia do Espírito Santo -Ifes - Campus Nova Venécia.
} 
a escola, sem dúvida, terá mais sucesso como instituição flexível, com novos modelos de avaliação e sistemas de convivência, que considerem a diversidade da condição do aluno da EJA, atendendo às dimensões do desenvolvimento, acompanhando e facilitando um projeto de vida, desenvolvendo o sentido de pertencimento, identificando-se com os jovens.

Carrano (2008, p.156), diz que a escola se afirma como o espaço e tempo dos encontros entre os muitos sujeitos culturais que a fazem existir; assim, como educadores, faz parte de nossa tarefa levarmos em conta fundamentalmente aqueles que pretendemos educar.

É fundamental que lidemos com os jovens numa perspectiva que vá além dos conceitos da facilidade e redução de tempo para a conclusão e obtenção do certificado.

Dessa forma, este estudo se propôs a analisar quem é o jovem que ocupa a sala de aula da EJA da Escola Estadual de Ensino Fundamental e Médio "Antonio dos Santos Neves", discutindo sobre a identidade que eles constroem ao frequentarem as salas da EJA.

Analisar a identidade desses jovens não se mostra uma tarefa fácil, já que para isso é necessário refletir sobre conceitos complexos como identidade e juventude, assim como lidar com a especificidade que caracteriza os sujeitos jovens da referida comunidade. Nesse sentido, neste estudo, lidamos com dados recolhidos com 13 jovens pertencentes à $8^{\text {a }}$ série.

Inicialmente, na escola onde foi realizada a pesquisa só era oferecido o ensino médio regular no turno noturno. No dia 01 de Agosto de 1995 foi feita a Regularização da Criação do Curso Ensino Fundamental e Médio, na modalidade EJA, mas entrou em prática somente no 20 semestre do ano letivo de 2005. A partir de então, ensino médio regular e EJA passaram a ser oferecidos aos alunos do turno noturno.

A abertura do curso no ano de 2005 fez-se necessária em virtude dos acordos de municipalização efetuados no mesmo ano, sendo que o mesmo funcionava no turno noturno da Escola Estadual Fundamental "Profa. Ubaldina Santo Amaro do Amaral", que foi municipalizada na época. Esta escola só oferecia esta modalidade de ensino no turno noturno e no diurno era oferecido ensino fundamental das séries iniciais. A EEEFM "Antonio dos Santos Neves", por situar-se próxima à escola Ubaldina e oferecendo espaço físico, decidiu implantar os cursos de Suplência Fase II e III, na Modalidade da EJA.

Feitas essas considerações, iremos, neste artigo, abordar o conceito de identidade, já que buscaremos analisar como a mesma é construída por estes jovens na relação com a escola como instituição social, se existem elementos que permitam saber quem eles são. Posteriormente levantaremos a discussão conceitual do termo juventude para avançar em práticas educativas que favoreçam sua especificidade. Antes dessa incursão, no entanto, são necessários alguns apontamentos metodológicos.

\section{METODOLOGIA}

A pesquisa aqui apresentada classifica-se como qualitativa de caráter descritivo, pois "tem como objetivo primordial a descrição das características de determinada população ou fenômeno ou, então, o estabelecimento de relações entre as variáveis" (GIL, 2002, p.42). Uma das características mais significativas desse tipo de investigação está na utilização de técnicas padronizadas de coleta de dados, tais como questionário e a observação sistemática. Seu objetivo principal consiste em interpretar o fenômeno segundo a perspectiva dos participantes da situação estudada - no nosso caso, os jovens da EJA - e a partir daí situar as interpretações e fenômenos.

Para desenvolver a reflexão sobre os jovens na EJA foram seguidos dois procedimentos metodológicos. Na primeira fase da pesquisa foi aplicado um questionário sobre o perfil 
socioeconômico dos jovens e seus familiares. Os alunos responderam ao questionário na sala de aula com a permissão da professora e este foi recolhido imediatamente após as respostas. A postura dos alunos frente ao questionário foi de extrema curiosidade. Tivemos que dar explicações sobre a finalidade da pesquisa e todos se mostraram dispostos a contribuir respondendo atenciosamente e também se mostraram predispostos, apesar de envergonhados, a responderem às perguntas da entrevista que viria posteriormente.

Na segunda fase, após duas semanas da aplicação do questionário, esses jovens foram entrevistados individualmente numa conversa informal dentro da biblioteca da escola. Os alunos eram encaminhados pela professora regente à biblioteca da escola e estes foram ouvidos e suas respostas gravadas com o auxílio de uma câmera.

Os dados coletados por meio desses procedimentos possibilitaram a reflexão sobre a identidade dos jovens na EJA.

\section{IDENTIDADE}

Muitos são os autores que se dedicam ao termo identidade no sentido de definirem as características que nos remeteriam a ela. Woodward (2008) especifica essa discussão quando questiona em seu livro Identidade e Diferenças se a identidade é fixa e se podemos encontrar uma "verdadeira". Ela ainda afirma que a identidade é marcada pelas diferenças, sendo elas a consciência identitária de grupo.

Já Hall (2001) propõe a impossibilidade de oferecer afirmações conclusivas sobre as alegações e proposições teóricas que estão sendo apresentadas sobre identidade, analisando uma possível crise levantada a partir da ascensão de novas identidades que fragmentam o indivíduo moderno, antes visto como um sujeito unificado. $O$ autor afirma o seguinte:

[...] à medida em que os sistemas de significação e representação cultural se multiplicam, somos confrontados por uma multiplicidade desconcertante e cambiante de identidades possíveis, com cada uma das quais poderíamos nos identificar - ao menos temporariamente (HALL, 2001, p. 12).

O mesmo autor aponta três concepções pelas quais passou a identidade na sua variante teórica para mostrar as transformações da concepção de sujeito ao longo de diferentes contextos: a identidade do sujeito do lluminismo, a do sujeito sociológico e a do sujeito pós-moderno.

O sujeito do lluminismo era identificado:

[...] como um indivíduo totalmente centrado, unificado, dotado das capacidades da razão, de consciência e de ação, cujo "centro" consistia num núcleo interior, que emergia pela primeira vez quando o sujeito nascia e com ele se desenvolvia, ainda que permanecendo essencialmente o mesmo - contínuo ou "idêntico" a ele - ao longo da existência do indivíduo. O centro essencial do eu era a identidade de uma pessoa (HALL, 2001, p. 10).

Nessa concepção apontada pelo autor o sujeito é caracterizado por um sentimento estável de sua própria identidade. Esse pensamento surgiu pautado em alguns movimentos que contribuíram para sua emergência, como 
[...] a Reforma e o Protestantismo, que libertaram a consciência individual das instituições religiosas da Igreja e a expuseram diretamente aos olhos de Deus; o Humanismo Renascentista, que colocou o Homem (sic) no centro do universo; as revoluções científicas, que conferiram ao Homem a faculdade e as capacidades para inquirir, investigar e decifrar os mistérios da Natureza; e o lluminismo, centrado na imagem do Homem racional, científico, libertado do dogma e da intolerância, e diante do qual se estendia a totalidade da história humana, para ser compreendida e dominada (HALL, 2001, p.26).

Já a noção de sujeito sociológico, contrária a do lluminismo, consiste na interação do eu com a sociedade. À medida que as sociedades foram tornando-se mais complexas, elas adquiriram uma forma mais coletiva e social, emergindo uma concepção social de sujeito.

A noção de sujeito sociológico refletia a crescente complexidade do mundo moderno e a consciência de que este núcleo interior do sujeito não era autônomo e autossuficiente, mas era formado na relação com "outras pessoas importantes para ele", que mediavam para o sujeito os valores, sentidos e símbolos - a cultura dos mundos que ele/ela habitava. [...] O sujeito ainda tem um núcleo ou essência interior que é o "eu real", mas este é formado e modificado num diálogo contínuo com os mundos naturais "exteriores" e as identidades que esses mundos oferecem (HALL, 2001, p.11).

O individualismo e o racionalismo são substituídos pelo conceito de um indivíduo coletivo em processos de grupos e como sua formação se dá através dessas relações sociais. Seria então, como diz Hall (2001, p.31) "a 'internalização' do exterior no sujeito e essa 'externalização' do interior através da ação do mundo social constitui a descrição sociológica primária do sujeito moderno e estão compreendidas na teoria da socialização".

Dos movimentos estéticos, intelectuais e com o surgimento do Modernismo, começa a surgir uma outra concepção do sujeito e da identidade, mais perturbadora do que a do sujeito cartesiano e a do sujeito sociológico citadas anteriormente. Aqui o sujeito é isolado, exilado ou alienado.

A argumentação é que essas concepções mudaram para uma visão de identidade pautada na variedade, comportada de várias reflexões conceptualizando o sujeito moderno como não tendo uma identidade permanente.

Hall (2001, p.12) afirma que o "próprio processo de identificação, através do qual nos projetamos em nossas identidades culturais tornou-se mais provisório, variável e problemático e é isso que produz o sujeito pós-moderno". Esse tipo de sujeito é construído historicamente e não biologicamente como sugere o sujeito do lluminismo que entende ser a identidade unificada desde o nascimento.

Alguns avanços na teoria social e nas ciências humanas ocorridos na segunda metade do século XX marcaram essa transição. Uma foi o descentramento final do sujeito cartesiano, em que o indivíduo era autor e agente da sua história. À luz das teorias de Marx, que eram contrárias a qualquer noção de essência universal do homem, os ramos do pensamento moderno tiveram um impacto considerável.

A identidade fixa e unificada também é deslocada com as teorias de Freud e a descoberta do inconsciente:

A teoria de Freud de que nossas identidades, nossa sexualidade e a estrutura de nossos desejos são formadas com base em processos psíquicos e simbólicos do inconsciente, que funciona de acordo com uma 'lógica' muito diferente daquela da 
Razão, arrasa com o conceito do sujeito cognoscente e racional provido de uma identidade fixa e unificada - o 'penso, logo existo', do sujeito de Descartes. Este aspecto do trabalho de Freud tem tido também um profundo impacto sobre o pensamento moderno nas três últimas décadas (HALL, 2001, p. 36).

O estudo da teoria de Hall é contrário ao desenvolvimento natural do indivíduo e leva a crer a sua formação em relação com os outros ao longo do tempo através de processos inconscientes. Ela permanece incompleta, estando sempre em processo de formação. Sendo assim, a identidade não é uma coisa acabada e sim um processo em andamento.

\begin{abstract}
A identidade surge não tanto da plenitude da identidade que já está dentro de nós como indivíduos, mas de uma falta de inteireza que é "preenchida" a partir de nosso exterior, pelas formas através das quais nós imaginamos ser vistos por outros. Psicanaliticamente, nós continuamos buscando a "identidade" e construindo biografias que tecem as diferentes partes de nossos eus divididos numa unidade porque procuramos recapturar esse prazer fantasiado da plenitude (HALL, 2001, p. 39).
\end{abstract}

Destaca-se também o poder disciplinar que se desenvolveu nas instituições do século XIX, em que a escola era tida como forma de regular e vigiar a espécie humana.

Os novos movimentos sociais também propiciaram a transição em relação às teorias sobre a identidade, pois constituíram a política das identidades em que cada movimento estava em busca da identidade de seus sustentadores. O feminismo, por exemplo, causou impacto tanto como uma crítica teórica quanto como um movimento social porque se expandiu para incluir a formação das identidades sexuais e de gênero.

A globalização causou impacto na identidade cultural quanto ao seu caráter dinâmico. As sociedades modernas sofrem mudanças permanentes e muito rápidas que influenciam na alteração íntima e pessoal da existência humana. Uma sociedade que não é delimitada, que não é unificada, caracterizada por rupturas constantes produz também uma variedade de sujeitos em diferentes posições, formando uma estrutura de identidade permanentemente aberta.

Quanto mais a vida social se torna mediada pelo mercado global de estilos, lugares e imagens, pelas viagens internacionais, pelas imagens da mídia e pelos sistemas de comunicação globalmente interligados, mais as identidades se tornam desvinculadas - desalojadas - de tempos, lugares, histórias e tradições específicos e parecem "flutuar livremente" (HALL, 2001, p. 75).

Essas conceituações levantadas se prestam como ponto de apoio para desenvolver argumentos que embasam algum tipo de identidade construída pelos jovens na escola. Entende-se, a partir dos conceitos levantados, que a identidade é mutável, mas que pode existir mesmo que seja temporariamente. Isso motiva a nossa pesquisa no sentido de encontrar respostas para algumas questões: Como os jovens se veem no contexto da EJA? Quais seus valores e ideais? O que eles priorizam? As respostas a essas perguntas podem ajudar no trabalho com grupos construídos na EJA. O conjunto de impressões que os identificam, seus valores e suas ideias serão o objeto de leitura para sua interpretação. 


\section{OS JOVENS DA EJA}

Os estudos referentes à juventude classificam convencionalmente os jovens pela faixa etária de 15 a 24 anos de idade, tendo por base os critérios da Organização Mundial da Saúde (OMS) e da Organização das Nações Unidas (ONU). Esse critério de faixa etária está sempre presente como base prévia de uma definição de juventude.

Outro critério que permeia a definição de juventude é o sócio-cultural que abrange muito mais do que limites etários restritos. Ela passa a ser definida como categoria social, significando uma série de comportamentos e atitudes a ela atribuídos.

Dayrell (2007, p.157), buscando compreender os jovens como sujeitos sociais, afirma que

Construir uma noção de juventude na diversidade implica, em primeiro lugar, considerá-la não mais presa a critérios rígidos, mas, sim, como parte de um processo de crescimento mais totalizante, que ganha contornos específicos no conjunto das experiências vivenciadas pelos indivíduos no seu contexto social. Significa não entender a juventude como uma etapa com um fim predeterminado, muito menos como um momento de preparação que será superado com o chegar da vida adulta.

As imagens com as quais nos deparamos no cotidiano sobre juventude acabam por interferir na maneira de compreender os jovens. Ora ela é vista na condição de transitoriedade, ora ela é vista como tempo de liberdade, prazer, de expressão de comportamentos exóticos.

Vista na sua condição de transitoriedade, a juventude passa a ser analisada como uma passagem para um estágio considerado mais estável que é a vida adulta, negando a vivência no presente. Como afirma Dayrell, (2007, p. 156) "em nome do 'vir a ser' do aluno, tende-se a negar o presente vivido do jovem como espaço válido de formação, assim como as questões existenciais que eles expõem, bem mais amplas do que apenas o futuro".

Apontando essas questões, o autor expõe os cuidados que devemos ter para não corrermos o risco de analisarmos os jovens de forma negativa, o que prejudicaria a compreensão dos modos pelos quais eles constroem suas experiências. Para o autor,

Construir uma noção de juventude na perspectiva da diversidade implica, em primeiro lugar, considerá-la não mais presa a critérios rígidos, mas, sim, como parte de um processo de crescimento mais totalizante, que ganha contornos específicos no conjunto das experiências vivenciadas pelos indivíduos no seu contexto social. Significa não entender a juventude como uma etapa com um fim predeterminado, muito menos como um momento de preparação que será superado com o chegar da vida adulta (DAYRELL, 2007, p 157).

A definição exata do conceito de juventude ainda está permeada de conotações, mas isso não impede de identificar esse campo tão dinâmico e heterogêneo. Ao abordar a juventude na EJA, Arroyo $(2008$, p.21) afirma que

[...] o que há de mais esperançoso na configuração da EJA como campo específico de educação é o protagonismo da juventude. Esse tempo da vida foi visto apenas como uma etapa preparatória para a vida adulta. Um tempo provisório. Nas últimas décadas, vem se revelando como um tempo humano, social, cultural, identitário que se faz presente nos diversos espaços da sociedade, nos movimentos sociais, na mídia, no cinema, nas artes, na cultura... Um tempo que traz suas 
marcas de socialização e sociablidade, de formação e de intervenção. A juventude e a vida adulta como um tempo de direitos humanos, mas também de sua negação.

Em geral, a juventude da EJA é tratada como uma massa de alunos marcados pela exclusão, sendo eles rotulados como repetentes e defasados. Tais rótulos deixam de lado, muitas vezes, dimensões de sua condição humana fundamentais para a experiência educativa, tais como as apontadas por Arroyo (2008).

A passagem desses jovens pela escola regular, na maioria das vezes, foi marcada pelo insucesso no desempenho educacional. Eles já se inserem na EJA impregnados desses estigmas revelando assim uma autoestima baixa, repleta de insegurança frente aos desafios que lhes são impostos. Arroyo nos mostra isso, quando diz que

\begin{abstract}
A EJA nomeia os jovens e adultos pela sua realidade social: oprimidos, pobres, sem terra, sem teto, sem horizonte. Pode ser um retrocesso encobrir essa realidade brutal sob nomes mais nossos, de nosso discurso como escolares, como pesquisadores ou formuladores de políticas: repetentes, defasados, aceleráveis, analfabetos, candidatos à suplência, discriminados, empregáveis... Esses nomes escolares deixam de fora dimensões de sua condição humana que são fundamentais para as experiências de educação (ARROYO, 2008, p.223).
\end{abstract}

Uma outra visão negativa apontada para os jovens em relação ao seu ingresso na Educação de Jovens e Adultos é a falta de entrosamento com os adultos lá presentes, como se os jovens não fossem capazes de se envolver com os outros grupos de relacionamento a não ser o deles. Para Carrano (apud FERNANDES, 2005, p. 3), "alguns professores e também alunos mais idosos parecem convencidos de que os jovens alunos da EJA vieram para perturbar e desestabilizar a ordem supletiva escolar".

Alguns mitos sobre os jovens da EJA precisam ser desconstruídos. Um novo olhar sobre eles já é o indício de novas propostas para pensá-los não mais como excluídos e indicar possivelmente ações no sentido da inclusão desses sujeitos. Faz-se necessário não mais reduzi-los à condição de alunos assim como ampliar o papel da escola para além daquele voltado para a instrução. Dessa forma, é possível perceber as várias possibilidades de formação humana escamoteadas pela percepção restrita do papel da educação escolar.

No desenvolvimento da pesquisa os resultados levantam três categorias sobre o jovem da pesquisa. São elas: $O$ jovem da EJA em relação a si mesmo, o jovem em relação à escola e o jovem em relação ao mercado de trabalho.

\title{
O jovem em relação a si mesmo
}

Do total de 13 jovens pesquisados, $40 \%$ eram do sexo feminino e $60 \%$ do sexo masculino. Os jovens eram de família com renda familiar que, em $66 \%$ dos casos, não ultrapassava um salário mínimo e em $27 \%$ era de 1 a 3 salários. Apenas um jovem tinha renda familiar de 3 a 5 salários mínimos.

Influenciados pelo sentimento de desenvolvimento pessoal e profissional esses jovens reconhecem que vivem num presente que não é o ideal e projetam para si um novo futuro. As velhas certezas dos jovens que antes largaram os estudos como dispensável para a realização dos seus projetos têm sido postas em questão. Agora, se dispõem a mudar de posição, fato que nos reporta a Woodward (2008, p. 30), quando afirma que 
[...] nós somos, na verdade, diferentemente posicionados pelas diferentes expectativas e restrições sociais envolvidas em cada uma dessas diferentes situações, representando-nos, diante dos outros, de forma diferente em cada um desses contextos. Em um certo sentido, somos posicionados - e também posicionamos a nós mesmo - de acordo com os 'campos sociais' nos quais estamos atuando.

O sentimento do significado a escola encontra outra interpretação baseado em que não se pode ter sucesso sem antes completar a escolaridade. E essa relação com as pessoas vai deixando isso bem claro para eles:

Lá em Vitória eu fiz uma... eu fiz um curso pra fazer prova pra ser policial, só que eu não consegui porque não tinha estudo, aí eu tinha que acabar de fazer o estudo pra mim conseguir entrar, pra fazer esse curso, aí por isso que eu voltei pra estudar (CLAUDINÉIA, 21 anos).

As necessidades desses jovens estão em estudo porque eles se veem com expectativas de mudanças e "a identidade somente se torna uma questão quando está em crise, quando algo que se supõe como fixo, coerente e estável é deslocado pela experiência da dúvida e da incerteza" (MERCER, apud HALL, 2001, p.9).

Muitos dos jovens pesquisados objetivaram mudanças para si e essa mudança representa esse processo de transformação para a definição de sua própria essência como sujeitos:

Eu era muito descabeçada, agora eu consertei mais ou menos... (ALESSANDRA, 24 anos).

Eu mudei pra melhor estudando aqui. Na hora de tratar as pessoas, na hora de conversar (CLEIDIANE, 21 anos).

Agora eu sou mais responsável e esforçado (FERNANDO, 16 anos).

Essa formação que eles querem e procuram, convencidos de que precisam de mais para a sua realização, reafirma a discussão de Hall $(2001$, p.38), quando afirma que:

A identidade é realmente algo formado ao longo do tempo através de processos inconscientes, e não algo inato, existente na consciência no momento do nascimento. Existe sempre 'algo imaginário' ou fantasiado sobre a sua unidade. Ela permanece sempre incompleta, está sempre 'em processo', sempre 'sendo formada'.

A expectativa desses jovens é de uma formação que os leve além do que já conquistaram. A evidência é de que estão em uma posição de transformação; querem ser melhores investindo no estudo como ponto de partida para suas realizações. Quando assumem essa posição, mostram-se maduros e responsáveis, atitudes que antes não se relacionavam às visões da juventude que eram, muitas vezes, marcadas por crises e conflitos. A juventude aqui entrevistada sabe muito bem o que quer da vida para deixar de ser uma massa de alunos marcados pelo insucesso no ensino regular. 


\section{0 jovem em relação à escola}

Analisando o conteúdo das entrevistas, constata-se que a maioria viveu uma trajetória escolar atribulada com um atraso significativo, embora a escolaridade deles seja ainda maior que a dos seus pais, cujo histórico é de uma escolarização incompleta e bastante precária. Nenhum dos entrevistados tivera pais com ensino médio completo. Dos dados coletados sobre os pais dos alunos entrevistados, verificou-se que a maioria (8 mães (53\%) e 5 pais (34\%) tinha Ensino Fundamental incompleto até a 4a série, podendo ainda destacar dentre eles analfabetos (dois pais e uma mãe).

Essa não familiaridade com a cultura escolar por parte dos pais poderia supor a desvalorização da educação pelas famílias, mas isso não foi confirmado nos depoimentos, pois apesar disso, os jovens atribuem sentidos positivos à escola, vendo nela uma opção para mudar de vida e adquirir um melhor emprego, aumentando o orçamento familiar.

Esses jovens da pesquisa viveram uma trajetória incerta feita de idas e vindas na escola, contribuindo, assim, para uma defasagem série/idade. Brunel (2004), ao estudar os jovens na EJA quanto a essa defasagem relata que fatores pedagógicos, políticos, legais e estruturais fazem com que muitos jovens procurem cada vez mais esta modalidade e cada ano mais precocemente.

No decorrer dessa pesquisa alguns fatos que influenciaram o ingresso na EJA ficaram evidentes na fala de alguns alunos:

Nunca parei de estudar, mas agora eu passei pra noite, pra EJA por questão de arranjar um serviço e aprendizagem. Pra mim aprender alguma coisa né? (ALEX, 15 anos).

Ninguém me mandou vim pra cá não. Eu que quis vim. Eu táva atrasado no Ensino Regular e vim pra EJA e to trabalhando agora também (BRUNO, 17 anos).

Eu estudava a tarde e vim pra noite. Ah, eu vim por motivo de briga, a diretora falou que faltava poucos dias pra eu ser expulso aí me mandou pra noite (JOHN LENON, 15 anos).

Essa realidade expressa a trajetória desses jovens, marcada por descompromissos do sistema no que se refere ao ensino público. Na maioria das vezes atribuem exclusivamente a si um fracasso que não é só deles. Brunel (2004) afirma que o aluno quer ser ouvido, quer opinar. Só ficará calado em sala de aula se esta não lhe suscitar alguma reação, se o que ele aprende não lhe causar nenhum interesse.

A escola da sua gênese até os nossos dias, não modificou muito as suas práticas pedagógicas, e talvez, também por isso, ela se encontre em crise. Na maioria de nossas escolas, sejam elas públicas ou privadas, os alunos são obrigados a decorar longos textos, a disposição das cadeiras é a mesma na maioria das escolas. 0 discurso dos professores frequentemente é o mesmo após muitos anos de magistério (BRUNEL, 2004, p. 33).

Nessa linha de pensamento, Charlot (2000) diz que o que é aprendido só pode ser apropriado pelo sujeito se despertar nele certos ecos que fazem sentido para ele.

Alguns jovens entrevistados demonstram uma descrença na possibilidade de êxito no sistema educacional quando mencionam somente a escolarização como forma de certificação. Questionados sobre o que esperam que a escola lhes ofereça alguns indicam o diploma como a única forma de contribuição, não se importando com a aprendizagem em si:

Ô meu... o que eu quero mesmo, desejo mesmo? É acabar os estudo, é pegar o diploma, é isso, só o diploma (MASTRANGELO, 24 anos). 
Eu quero é pegar o diploma pra poder fazer a faculdade (GEOVANI, 16 anos.).

Ah, eu quero pegar o diploma e ir embora pra onde ta os meus tios (BRUNO, 17 anos).

Tais falas demonstram que, para eles, a educação escolar carece de sentido, manifestando, assim, uma postura paralelismo em relação à escola: eles estão presentes, mas não inseridos. Para os jovens com essa mentalidade há uma negação da Educação em si. Pela experiência, eles sabem que a baixa escolaridade limita a inserção no mercado de trabalho, assim, o certificado cumpre apenas uma função seletiva sem relação com o conhecimento:

Às vezes a gente vai procurar serviço aí eles perguntam pra gente, a primeira coisa, qual o estudo que a gente tem, se fez alguma coisa assim. Aí acho que ajuda muito né, ter estudo, mesmo que às vezes cê não precisa saber de nada, apenas ler $e$ escrever já é o suficiente, mas ajuda o diploma (MASTRANGELO, 24 anos).

Charlot (2000, p. 47), nesse sentido, diz que:

[...] talvez pudéssemos indagar se essa separação que os jovens fazem entre a "educação" (o aprendizado dos valores ético-morais) e aquilo que a escola ensina não seria consequência da própria maneira como se dá o processo ensino/aprendizagem. Em outras palavras, talvez o pouco valor que os jovens conferem ao aprendizado de conteúdos curriculares não seja resultante do seu "desinteresse", e sim da sua dificuldade de encontrar um "sentido" para aquilo que os professores ensinam [...].

É fato que o professor é um importante ator no processo educacional e é desafiado diariamente a encontrar soluções de estímulo que possibilitem aos seus alunos inserir-se no espaço escolar criando condições para a aprendizagem. Contudo, da mesma forma, sua prática pode contribuir para o fracasso quando suas instruções forem contrárias às habilidades dos alunos e não permitirem a sua expressividade.

Não há uma única visão dos jovens pesquisados em relação aos professores. Alguns deles mostraram uma postura amigável, sem atrito ou tensão que pudesse motivar algum tipo de desinteresse pelos estudos.

Gosto dos meus professores. Eles são bons, ajudam a gente (Jones, 17 anos).

O relacionamento com meus professores é muito bom. Todos, assim, ajudam a gente demais. E tem aquele dia que a criança fica doente, tem aquele dia que chegou tarde do trabalho e se ficou uma prova, um trabalho pra trás, eles se esforçam a repor pra gente. Ajuda bastante (CLAUDINÉIA, 24 anos).

Outros alunos demonstraram certo tipo de empatia por alguns professores, como podemos comprovar nesses depoimentos:

Rapaz, tem uns professores que a gente desanima um pouco de estudar. Eles são meio chatos, bem exigentes. Tem certas coisas que a gente coloca uma barreira na gente que a gente mesmo não quer aceitar aquela pessoa do jeito que ela é. Por isso que a gente fica com bobeira (MASTRANGELO, 24 anos). 
Ah, tem hora que eles são bons, tem hora que eles são ruins. Tem hora que a gente se desentende. Ah, tem hora que a gente vai perguntar uma coisa, não sei o que e... pam... ai a gente fica nervoso, discuti com o professor e é melhor deixar pra lá (ALEX, 15 anos).

Carrano (2008, p.160) diz que o educador atento precisa ser capaz de indagar o que os grupos culturais da juventude têm a nos dizer. Uma das suas reflexões em relação à apatia ou desinteresse dos jovens é a necessidade da disposição ao diálogo, o que traria outros contextos educativos que poderiam ser explorados. Nesse sentido, o diálogo estabeleceria uma relação de parceria entre eles desencadeando nos alunos um processo de descobertas para uma concepção educativa adequada a seus interesses.

Esse diálogo fecundo, como também relata Arroyo (2008) somente será possível se a EJA não for forçada a se encaixar em modelos e concepções de educação próprios das clássicas modalidades de ensino.

Desse modo ela não deveria ter uma concepção tradicional e regulatória do tempo escolar e das práticas a serem desenvolvidas em seu interior. A valorização dos saberes e a cultura popular são fundamentais para se construir ou até mesmo reconstruir o conhecimento.

Trata-se de incorporar uma das matizes mais perenes da formação humana, da construção e apreensão da cultura e do conhecimento: reconhecer a pluralidade dos tempos, espaços e relações onde nos constituímos humanos, sociais, cognitivos, culturais... Reconhecer a cultura como matriz da educação (ARROYO, 2008, p. 228).

Os jovens no contexto da EJA veem-se mais responsáveis e mais conscientes do significado que a escola adquire no contexto social. Nela eles admitem encontrar a possibilidade de integrar-se nesse contexto através de uma possível autonomia financeira. É na escola que se conseguem aspirações de um digno lugar na sociedade.

\section{0 jovem e o mercado de trabalho}

Os dados do questionário mostram que $80 \%$ dos jovens entrevistados trabalham em atividades como vendedor, agricultor, trabalhador rural, braçal, marceneiro, pedreiro, diarista e doméstica.

O trabalho é considerado tanto como motivador da evasão dos alunos como uma das causas mais evidentes para o ingresso na EJA. Alguns jovens submeteram-se a trabalhar para minimizar as dificuldades financeiras da família e, consequentemente, não conseguem conciliar escola e trabalho. Entre trabalhar e estudar o peso maior era trabalhar para superar as necessidades imediatas.

Ah, eu ja parei por bobeira minha mesmo. Outras vezes, quando eu tava trabalhando, chegava muito cansado e ficava desanimado e parava. Eu voltei a estudar por vontade, pra seguir uma carreira, ter o diploma pra poder seguir adiante com os estudos, uma carreira profissional bem sucedida e escolhi a EJA pra pode me adiantar logo nas matérias e não ficar atrasado, tão atrasado (UILSON, 19 anos).

Ah, eu parei por bobeira minha mesmo. Outras vezes, quando eu tava trabalhando, chegava muito cansado e ficava desanimado e parava (MASTRANGELO, 24 anos). 
O posterior retorno à escola possibilitaria uma reconstrução na trajetória do trabalho e a Educação de Jovens e Adultos foi a alternativa de escolarização preferida por esses jovens aliada a uma maior rapidez na conclusão do curso.

Analisando também os rumos da história na Revolução Industrial com a descoberta científica das máquinas e o favorecimento de outro perfil de qualificação do trabalhador, a escola passa a ser condição de acesso e permanência no emprego (BRUNEL, 2004).

Os jovens da EJA, convencidos de que necessitam do conhecimento científico, percebem que a escola é o espaço institucional privilegiado para essa transmissão do conhecimento e que através dela as relações econômicas sociais podem ser modificadas.

Eu voltei pra EJA porque eu tinha vontade de aprender mais coisas. To aqui e vou até o fim (ALESSANDRA, 24 anos).

Hoje em dia tudo exige, né? Pra uma profissão, pra tudo hoje exige escolaridade, né? Aqui na EJA dá pra aprender bastante, né? Mesmo questão dois anos em um, mas dá pra aprender bastante, e é um meio de terminar mais rápido, né? (CLAUDINÉIA, 24 anos).

Charlot (2000, p.147) diz que

se esses jovens devem, desse modo, conquistar essas aprendizagens, é para ingressar em um mundo humano, habitar esse mundo, nele desenvolver competências e encontrar referências, construir suas relações com os outros, construir-se a si próprios como sujeitos humanos e se fazer reconhecer como tais (tornar-se alguém).

A prioridade que os jovens da EJA dão para a escola como forma de inserção no mercado de trabalho é uma de suas peculiaridades. Essa similaridade demonstra também que esses indivíduos não estão e nem são desorientados ou sem perspectivas, assim nomeados por muitos até então. Esses jovens ocupam uma posição em comum no contexto da EJA quando depositam nela essa relação com o trabalho. Muitos revelaram que entraram no mundo de trabalho precocemente e expressam uma experiência que ainda não é a ideal e essa visão para um melhor emprego passa a ser tão almejada não só no sentido de uma autonomia financeira, mas também com uma autonomia pessoal. Eles, além do ganho salarial, desejam um reconhecimento pessoal.

\footnotetext{
Ah, eu quero conseguir o diploma e seguir em diante, uma boa educação que possa trazer coisas boas pra mim e pra tudo (ALEX, 15 anos).

Eu quero da escola o diploma... pra mim ser alguém melhor na vida (CLEIDIANE, 21 anos).

Eu quero uma oportunidade no Mercado de emprego, assim, alguma coisa que me encaminhe pra um emprego, alguma coisa assim (JONES, 17 anos).
}

O desejo, sobretudo, de ingressar no mercado de trabalho lhes garante uma concepção de identidade. O papel que eles assumem como estudantes da EJA objetivando uma ascensão ou inserção no mercado de trabalho, faz com que eles adquiram uma nova postura, confirmando a ideia de que "as posições que assumimos e com as quais nos identificamos constituem nossas identidades" (WOODWARD, 2008, p.55). 


\section{CONCLUSÃO}

No início desta pesquisa foi levantada a discussão sobre a necessidade de compreender os educandos, nesse caso os jovens da EJA da EEFM "Antonio dos Santos Neves", para além da sua condição de aluno, estabelecendo uma relação de troca de experiências.

Depois da análise dos depoimentos e da entrevista realizados com esses jovens fica fácil compreender a relação que eles têm com a escola, onde buscam qualificação para o mercado de trabalho, reconhecendo que precisam recuperar o tempo perdido causado pelas inúmeras razões que os fizeram evadir anteriormente. Em todas as entrevistas, percebeu-se no discurso dos jovens que somente através da escola podem almejar novas oportunidades em relação ao mercado de trabalho e que precisavam rever a sua própria vida junto com a sua prática profissional. Isso faz surgir entre eles uma identidade coletiva que facilita o trabalho na construção do conhecimento.

É fato que, alguns jovens, mostram-se conscientes também de que nem sempre a escola oferece uma educação atraente e de que a permanência deles nela é motivada pela certificação que acaba se transformando no único elo entre a escola e a sociedade.

Essa reflexão feita pelos jovens é que causa a inquietação no sentido de conhecê-los para poder transformar a EJA numa educação mais atraente e de melhor qualidade. Este é um dos grandes desafios na EJA: atribuir sentidos aos jovens em relação com o saber escolar.

Já podemos identificá-los também como seres de origens diversas com inúmeros conhecimentos adquiridos ao longo de sua história de vida. E é esse conhecimento que eles já têm que não deve ser desconsiderado, mas sim transformado na relação com seus colegas de turma, com seus professores e todos que fazem parte do ambiente escolar.

Isso nos ajuda a retomar o papel determinante que tem o professor na vida desses jovens educandos. Sua atitude deve estar impregnada de humildade e de simplicidade que possa enxergar o jovem despojado de preconceitos para uma reorganização do saber rumo à produção de um novo conhecimento.

A discussão e reflexão sobre a realidade social dos jovens deve ser ponto de partida para se estabelecer posturas tomadas em sala de aula quanto a produção de conhecimento estabelecendo uma relação entre o saber escolar e a prática social. Para que seja permitida essa relação o professor tem que ingressar na vida do aluno e tomar partido de suas idealizações.

A construção dessa relação entre professor e aluno é importante para a desvinculação que deve ter a Educação dos Jovens e Adultos dos conteúdos pragmáticos e mecanicistas relacionados nos livros didáticos como um processo de superação do currículo oficial empregado nas escolas. A proposta curricular deveria interagir o saber interdisciplinar, propiciando aos alunos o resgate da memória de sua história de vida para que superassem o conhecimento da realidade criando um novo saber.

Tal proposta, às vezes, é realizada a partir de ações idealistas e solitárias que sofrem inibições pela ausência de estímulos por parte dos demais membros da escola, que preferem permanecer na comodidade das práticas tradicionais de ensino. O professor não consegue caminhar sozinho e essa prática ideal com os jovens requer muita coragem e dedicação.

Finalizando, esse estudo faz brotar uma esperança de possibilidade de um trabalho que considere a posição do jovem da EJA para a construção do seu conhecimento, em especial para a região de Boa Esperança. É fato que nada é estável e as mudanças ocorrem incessantemente no universo escolar. Não encontraremos um caminho pronto para ser seguido, uma única resposta em meio a tantos questionamentos. $\mathrm{O}$ estudo com os jovens da EJA precisa ser inacabado pela necessidade que ele tem de ser contínuo.

Uma só reflexão não deve ser perdida em meio aos vários estudos e análises que precisam ser feitos cotidianamente no universo escolar. Os jovens da EJA precisam ser reconhecidos na sua diversidade e autenticidade. 


\section{REFERÊNCIAS}

ANDRADE, Eliane. A educação de Jovens e Adultos e os Jovens do "Último Turno". Disponível em: http://www.bdae.org.br/dspace/bitstream/123456789/928/1/tese.pdf. Acesso em 10 Nov. 2010.

ARROYO, Miguel. Educação de jovens-adultos: um campo de direitos e de responsabilidade pública. In: SOARES, Leôncio; GIOVANETTI, Maria Amélia Gomes de Castro; GOMES, Nilma Lino (orgs.). Diálogos na educação de jovens e adultos. Belo Horizonte: Autêntica, 2008.296p. p. 19-50.

BRUNEL, Carmen. Jovens cada vez mais jovens na educação de jovens e adultos. Porto Alegre: Mediação, 2004.

CARRANO, Paulo César Rodrigues. Identidades Juvenis e Escola. In: UNESCO. Construção coletiva: contribuições à educação de jovens e adultos. 2. Ed. Brasília: UNESCO, MEC, RAAAB, 2008, 362 p. p. 153-162.

CHARLOT, Bernard. Os jovens e o saber. Perspectivas mundiais. Porto Alegre: Artes Médicas, 2000.

DAYRELL, Juarez. O jovem como sujeito social. In: UNESCO/MEC/ANPEd. Juventude e Contemporaneidade. Brasília: UNESCO, MEC, ANPed, 2007. 284 p. p. 155-176.

FERNANDES, Andrea da Paixão. Jovens na EJA, Perspectiva do Direito e Transferências: Responsabilidade de quem? Disponível em: http://www.ulbra.br/3sbece/andreapf.pdf. Acesso em 13 de Jul. 2010.

GIL, Antonio Carlos. Como elaborar projetos de pesquisa. 4. ed. São Paulo, Atlas, 2002.

HALL, S. A identidade cultural na pós-modernidade. Tradução Tomás Tadeu da Silva, Guaracira Lopes Louro. 6. ed. Rio de Janeiro: DP\&A, 2001. 103 p. Título original: The question of cultural identity.

WOODWARD, Kathryn. Identidade e diferença: uma introdução teórica e conceitual. 8. ed. Petrópolis, RJ: Vozes, 2008. 